\title{
The role of ethical principles in health
and the implications for ethical codes
}

\author{
Alexander E Limentani East Kent Health Authority, Dover
}

\begin{abstract}
A common ethical code for everybody involved in health care is desirable, but there are important limitations to the role such a code could play. In order to understand these limitations the approach to ethics using principles and their application to medicine is discussed, and in particular the implications of their being prima facie. The expectation of what an ethical code can do changes depending on how ethical properties in general are understood. The difficulties encountered when ethical values are applied reactively to an objective world can be avoided by seeing them as a more integral part of our understanding of the world. It is concluded that an ethical code can establish important values and describe a common ethical context for health care but is of limited use in solving new and complex ethical problems.
\end{abstract}

(Fournal of Medical Ethics 1999;25:394-398)

Keywords: Ethical principles; codes of professional ethics; philosophical ethics; medical ethics

\section{Introduction}

Codes of ethics have been a longstanding element in the professional control of the behaviour of doctors, and indicate a commitment to act with integrity in extreme circumstances. ${ }^{1}$ When patients seek medical care they are not entering an ordinary social relationship; they often feel vulnerable but need to expose and share intimate and important aspects of their lives. Ethical codes of conduct offer some tangible protection to both patients and doctors in these circumstances. The Hippocratic Oath is perhaps the best known code of this kind, and is still administered in some medical schools in the UK and elsewhere, ${ }^{2}$ despite uncertainty about its origin and relevance. ${ }^{3}$ Some schools use a modernised version of the Hippocratic Oath or the Prayer of Maimonides, others use the Declaration of Geneva or their own institutional oath. More recently the General Medical Council has issued a code, Duties of a Doctor, ${ }^{4}$ in response to changes in society, the law and medical practice. Traditionally, codes were adopted and oaths taken exclusively by doctors, reflecting that professional health care was a matter mainly between the doctor and the patient.
Increasingly, many of the moral difficulties present day health care arise in complex organis tions where care is delivered by multidisciplinas clinical teams and influenced by a range of othefs including managers, boards and governments This, among other considerations, has led to the recent call for a code of ethics for all health caf professions, ${ }^{5}$ and follows a number of expressions of concern voiced about the general ethical sta of modern medicine. ${ }^{6}$ In their recent paper, to Berwick et al give ample illustration of the diverse and complex moral challenges facing contempछ rary health care workers, and say they have bees encouraged by many to seek a common ethicet basis for medical practice. ${ }^{5}$

Their concern is not an esoteric, specialist on ethics are a central element in the quality of day day clinical practice and of enormous importan to the care of patients. Even if codes have only small influence they are likely to be worthwhile. Most ethical codes cover a range of topics. The usually include some specific prohibitions, fr. example, forbidding euthanasia, or disclosure of secret information, but mainly they describe gent eral attitudes and expected forms of conduct, for example: "always to act for the benefit of patientis deliver bad news with understanding and sympa thy, not sit in moral judgement on any patient, and strive to cure where possible but to comfort always". " There are advantages to be gain through the adoption of an ethical code and having a common understanding of the ethical nature of medical practice. However, a code ma raise unrealistic expectations about its scope and some caution is required. It is important, in strie ing the right balance, to understand the role thot such a code can play.

Ethical codes work in a similar way to ethical principles, the use of which has received much attention in recent years. ${ }^{8}$ In fact, the principles approach is now the most generally accepted an influential school of thought among medical eth? cists and is highly relevant to the discussion of ethical codes. There are important limitations 10 the principles approach to ethics which app equally to ethical codes. The theory is most not 
bly described by Beauchamp and Childress, ${ }^{9}$ whose exposition is based on four principles: autonomy, non-maleficence, beneficence, and justice. These principles are seen as one of four tiers in a hierarchy of levels of analysis necessary for moral justification. At the first tier there are particular judgments which are justified at the second level by moral rules. These in turn are justified at the third level by principles, and principles are finally justified at the fourth level by more comprehensive ethical theory. Both the methodology ${ }^{10}$ and applicability ${ }^{11}$ of "principlism" have been challenged, as well as defended as a common framework for biomedical ethics. ${ }^{12}$ However, even their strongest supporters do not see principles as a complete or self-standing means of establishing ethical practice. Beauchamp and Childress explain that: "Principles guide us to actions, but we still need to assess a situation and formulate an appropriate response, and this assessment and response flow from character and training as much as from principles". Gillon subsequently called this: "the four principles and scope" approach to biomedical ethics. ${ }^{13}$

\section{How principles operate}

The expectation is that, in practice, ethical principles and codes will help in thinking through difficult moral issues and in defending subsequent decisions. Proponents of the principles approach claim that they offer a firm grounding for moral judgment that can be used to resolve ethical dilemmas and be given in justification of our actions. For example, doctors are frequently faced with the dilemma of deciding what information should be given to patients about their condition. On the one hand, it is important for patients to know as much as possible about their disease in order to respond appropriately and take proper account of its implications in the conduct of their lives. On the other hand, knowledge of some aspects of the disease, in particular, complications that may occur but are unlikely, may carry the certainty of causing unnecessary distress and anxiety. This knowledge itself may adversely affect the patient, detracting from the quality of remaining life, and thereby worsening the prognosis. The approach taken using principles is to consider the requirements of each relevant principle in turn. In this example they are: the principle of autonomy, requiring relevant information to be given to the patient who wishes to receive that information; non-maleficence, not causing harm to the patient (either by giving information inappropriately and causing unnecessary confusion or anxiety or against the patient's expressed wishes); and beneficence, wishing to promote the patient's general wellbeing to produce the best outcome. The moral process resulting from this method is one of weighing the conflicting thrusts of these different concerns and deciding, on balance, the best course of action.

An important benefit of using principles in medical ethics is the drawing together of a common core of issues which loosely unite ethical concerns in health care. Taken in isolation the principles themselves are desirable, attractive and morally sound (similar in character to that of virtues). ${ }^{14}$ However, on any particular occasion they may conflict with each other and will not provide a moral conclusion without further judgment. Hence the need to make an assessment of the particular instance in order to decide the extent to which each principle is compatible with the underlying moral, professional, religious, or political theories that individual clinicians may hold. The advocates of the principles approach argue that since the content of general principles is consistent with most theories their application is universal and they transcend most cultural boundaries. They also have the attraction of being consistent with common approaches to the teaching of ethics, in particular lending themselves to the method of casuistry where the desired principles can be woven into a description of the situation as part of a narrative style of teaching. ${ }^{15}$

\section{Principles as 'prima facie'}

Principles and the moral rules derived from them are not absolutely binding. Their status is best described as "prima facie", by which Beauchamp and Childress ${ }^{16}$ mean that a principle is a duty which is binding on all occasions unless it is in conflict with equal or stronger duties. Following Ross, ${ }^{17}$ Beauchamp and Childress determine overriding duty by locating "the greatest balance" of right over wrong in any circumstance where there is conflict between principles. Although not absolute, they are more than expendable rules of thumb:

"Because they are always morally relevant, they constitute strong moral reasons for performing the acts in question, although they may not always prevail over other prima facie duties. One's actual duty is thus determined by the balance of the respective weights of the competing prima facie duties in the situation. One might say that prima facie duties count even when they do not win." 18

The strength of principles lies in their being prima facie, but so does their weakness. Problems begin to emerge when we ask how we are to moderate between principles when they are in conflict. 
There is nothing internal or intrinsic to prima facie principles themselves that determines relative importance. For example, when there is a need for autonomy, how important is non-maleficence? On any particular occasion it may be of overwhelming importance or of little practical relevance. The reference must be, as Beauchamp and Childress correctly say, to a more basic and profound ethical system, but the precise form this should take is not inherent in the principles themselves. Whenever there is a testing moral case principles are silent and something more, beyond principles, is required. However, in practice they are often accepted at face value without direct reference to a more comprehensive ethical theory, and indeed, the danger is that they will obscure ethical theory rather than illuminate it. This difficulty is manifest when principles are used in explanation of moral judgment; they are given no explanation themselves other than their prior designation as prima facie, and cannot give moral theory grounding without circularity. ${ }^{19}$

In practice, does the prima facie nature of principles matter? Can it not be argued that principles give us a very useful method of reaching moral conclusions and are sufficiently secure in their generality to perform this task without recourse to more basic and specific moral theory? This is the position implied by the presentations of moral theory in many bioethical texts, where different moral systems are given only superficial consideration, often drawing no conclusions as to relative merit. As a result, when particular issues are considered the weight allocated to individual principles is usually presented independently from any direct connection with underlying moral theory. It is not seen as material that the agent has, for example, a deontological approach to duty or is a consequentialist. Whether right or wrong, this lack of connection has little practical relevance when the rights and wrongs of the particular case are obvious and not in dispute. However, it is of critical importance when moral judgments are difficult - as they invariably are in many of the moral dilemmas in medicine, for example, whether a health authority should offer an expensive new treatment for Alzheimer's disease to all patients even though it will mean hardship in other areas, or whether a managed care organisation should selectively enrol well people and avoids vulnerable populations. ${ }^{5}$ In these cases the basis of moral judgments and their justification are called into question, and it is insufficient to take principles as a guide to action without further reference.
Understanding the role of principles in medicine

The role principles can play in medicine influenced by the way ethics in general a conceived. Clinical practice has an intrins ethical component, however, in training and $\stackrel{\infty}{11}$ thinking about moral values clinicians frequent find that they share a particular ethical outloo that is consistent with a scientific approach to lif $\vec{b}$ and which treats ethics as a separate and secondt ary issue. Reality is seen primarily in terms of the objective, external, physical world, whilst contrast, values and ethics are seen as a separat subjective and personal realm. ${ }^{20}$ In following this division there are two components to making ca moral judgment. First there are the moral neutral facts of the case that are either true or false and about which one can have knowledge or belief. Second there are the ethical attitudes one can have in response to the situation which detef mine the rights and wrongs of the case and guid what action should follow. ${ }^{21}$ This process of applying principles to a particular situation shouk ideally be carried out objectively, with the subject deciding in a calm and detached manner the relfo tive importance of each theoretical principle. Ths relegation of the ethical aspects of the world to $\bar{a}$ secondary and distinct subject is at the root of the difficulties encountered in subsequent ethic debate. As soon as a division is established on issue tends to overshadow any further ethical con sideration: how are the two realms of thougl related and how can ethical value be derived from the objective facts? The subsequent discussion range across a spectrum from extreme scepticism that there is any objective connection between facts and values to a rigid reductionism of fixeg relationships, usually utilitarian of one kind another.

Some attempts have been made to overcom these problems, by extending, through the work of social science and psychology, the idea of naturate ism beyond the natural sciences to include social and emotional aspects of life, in an effort to enable science to provide a more holistic picture of nature. However, the philosophical difficultie persist and cannot be overcome by simply extence ing the concept of nature to include social an psychological factors. The root of the problem lies more fundamentally with the conception of the relationship between ethics and other aspects of the world. In order to make further progressp instead of moral judgments being considered as separate, non-cognitive aspects of life, they are better understood as being an integral and inseparable part of empirical and factua properties. ${ }^{22}$ It is a mistake to think of an objectivi 
physical world which we then evaluate and from which we derive subjective ethical judgments. Values are better thought of as being already present in our conceptions of the world. This is not just a different interpretation but an epistemological claim about the way we understand the world, such that moral aspects are already present in our understanding and not thought of as being added by a further, secondary step. Here, moral properties are part of the world in the same way as any other property, including physical, social and emotional components. For example, cruelty can be recognised in the world and is not separable from the particular circumstances in which it is found. This view opens up the possibility of seeing the world and understanding what is going on in different ways. So, in the previous example of disclosure of information, although not giving information may be considered on the grounds of kindness (not wishing to cause additional anguish), it may also be seen as a cruel deception. The same set of circumstances can be seen in different ways and what is "right" depends on our point of view; and this in turn is shaped by cultural and social influences as well as our own individual views. The skill of a clinician lies in understanding the import of these competing views and in his or her ability to make a practical decision.

The arguments about providing a new drug for Alzheimer's disease hinge around cost and clinical effectiveness, but also crucially depend on how important Alzheimer's disease is thought to be and the extent to which it matters whether some respite is obtained in the course of the disease. The question about whether a managed care organisation should selectively enrol well people may be connected only to the financial viability of the organisation or it may be seen in the wider context of the health needs of the population as a whole and care of the most vulnerable groups, involving the question of where medical skills can provide the greatest benefit. However, unless we can see the particular possibility we cannot make a judgment about it. We make sense of the world in a factual and evaluative way as an integral and coherent process; it is the way the world is perceived that gives reasons to act morally. Principles and codes are still active as general background concepts establishing and describing issues that are important, but they have a limited role in explaining why we hold the values we do.

Although principles are derived in the context of an underlying moral theory, this is usually not explicit, and alone they cannot explain why a particular ethical position is important. If we try to use them in this way, instead of acting as a conduit for moral clarity they may intervene and obscure a clear ethical view of a situation. In any particular situation principles cannot ensure a correct balance of the indeterminate number of factors that can or could be taken into consideration, but they can help to focus on relevant moral issues. Principles are not the basis on which moral judgments are made, and they cannot give an explanatory basis for making those judgments; moral judgments themselves are more basic and no more profound reference is available. Once one understands the limitations of moral principles it is easier to see where they can play a useful role. They are markers that establish and define important concepts and can be used to describe important aspects of the positions we hold. They give shape to our moral environment and summarise our ethical positions.

This understanding of the role of principles and codes can allow a broader and more direct consideration of the moral issues. Instead of an inconclusive debate about conflicting principles, tending to narrow down the issues for consideration, this encourages broader and more robust moral discussion, requiring personal sensitivity as well as a trained appreciation of the many issues that can be relevant. We are more likely to understand why we feel the way we do and focus more clearly on comprehensive patient needs rather than taking a more limited perspective.

\section{Conclusion}

The content of general principles and codes represents concepts and values that can set the general ethical character and approach for health care. However, it is of little use in explaining individual ethical judgments. The implications for establishing ethical codes lie in recognising their potential value in describing the ethical environment and ethical attitudes that are shared by health care workers. Codes can also provide clear positions for a few headline ethical issues such as euthanasia, but cannot provide the certain answers to many of the ethical problems encountered in the course of everyday medical practice.

Alexander E Limentani, MBBS, FFPHM, $P h D$, is Director of Public Health, East Kent Health Authority, Dover. Address for correspondence:East Kent Health Authority, Protea House, New Bridge, Marine Parade, Dover, CT17 9AW. 


\section{References and notes}

1 Hurwitz B, Richardson R. Swearing to care: the resurgence in medical oaths. British Medical fournal 1997;315:1671-4.

2 Delamothe T. The Hippocratic Oath. British Medical fournal 1994;309:953.

3 Loudon I. The Hippocratic Oath. British Medical fournal 1994; 309:414.

4 General Medical Council. Duties of a doctor: guidance from the General Medical Council. London: General Medical Council, 1995.

5 Berwick D, Hiatt H, Laneway P, Smith R. An ethical code for everybody in health care. British Medical fournal 1997;315: 1633-4.

6 For example: Wetherall DJ. The inhumanity of medicine. British Medical fournal 1994;309:1671-2, and Mill M, Davies HTO, Macrae WA. Care of dying patients in hospital. British Medical fournal 1994;309:583-6.

7 Robin ED. The Hippocratic Oath updated. British Medical fournal 1994;309:96.

8 Gillon R, Lloyd A, eds. Principles of health care ethics. Chichester: J Wiley \& Sons Ltd, 1994.

9 Beauchamp TL, Childress JF. Principles of biomedical ethics [3rd ed]. Oxford: Oxford University Press, 1989.

10 Holm S. Not just autonomy - the principles of American biomedical ethics. Fournal of Medical Ethics 1995;21:332-8.

11 Maclean A. The elimination of morality. London: Routledge, 1993.

12 Gillon R. Defending 'the four principles' approach to biomedical ethics. Fournal of Medical Ethics 1995;21:323-4.

13 Gillon R. Medical ethics: four principles plus attention to scope. British Medical fournal 1994;309:184-8.
14 There are some similarities between the principles approach ethics and ethical systems based on virtues, such as that 8 Aristotle. Both raise the questions: where do they arise fror and what is their basis or reference. They usually rest onca descriptive analysis of nature and thus fall into the category "naturalism".

15 Jones AH. Literature and medicine: narrative ethics. Lan 1997;349:1243-6.

16 See reference $9: 51$.

17 Ross WD. The Foundations of ethics. Oxford: Clarendon Pres 1939.

18 See reference $9: 52$.

19 The problem of circularity and justification of ethicat judgments is present in virtue ethics and in most forms of ethical naturalism. The ethical values in question are derived from various natural aspects of the world and human nature whigh have already been judged to be desirable or not desirable.

20 This is a familiar ethical standpoint held by many ethicists an classically described by: Hume D. In: Selby-Bigge LA, e\$. Enquiries concerning human understanding and concerning tho principles of morals. Oxford: Clarendon Press, 1975.

21 McNaughton, D. Moral vision. Oxford: Blackwell, 1998. This position is that which he calls "moral non-cognitivism".

22 Recent examples of this position are: Norman R. Making sense of moral realism. Philosophical Investigations 1997;20,2:117-36. Diamond C. The realistic spirit. Wittgenstein, philosophy and if mind. Cambridge, Mass: The MIT Press, 1991, and McDowett J. Mind and world. Cambridge, Mass: Harvard University Pres. 1994. This position is broadly derived from the works of Wi\& genstein, for example: Wittgenstein L. In: Anscombe GEM, e@ Philosophical investigations. Oxford: Basil Blackwell, 1978.

\section{News and notes}

\section{Fifth European Forum on Quality Improvement in Health Care}

The organisers of the Fifth European Forum on Quality Improvement in Health Care, to be held in Amsterdam Rai, the Netherlands from 23 - 25 March 2000, are calling for papers.

Themes of the forum include:

Continuous quality improvement of patient care: what it is and how it can be implemented;

Leadership, culture change and change management: the major success factors in continuous quality improvement;
Collaboration between managers and clinical leaders; Health policy and quality improvement for lasting success in the health care system;

Implementing existing knowledge and disseminating best practices: our highest priority and our obligation to patients.

For further information please contact the BMA/BMJ Conference Unit, PO Box 295, London WC1H 9TE. Telephone: +44 (0) 171383 6478; fax: +44(0)171383 6869; email:MMitchell(a bma.org.uk 